\title{
Chu Teh-chun's Abstract Painting and Chinese and Western Modern Art
}

\author{
Feng Liu \\ School of Fine Arts \\ Jiangsu Normal University \\ Xuzhou, China 221116
}

\begin{abstract}
This paper summarizes the contribution of Chu Teh-chun's abstract painting to the development of Chinese and western modern art, including the continuation and development of modernism in the tide of fusion of Chinese and western culture of Chinese modern art, the development and breakthrough of European modern abstract painting and the artistic rejuvenation and dissemination in the modern transformation of Chinese traditional culture in the 20th Century.
\end{abstract}

Keywords-Chu Teh-chun; abstract painting; Chinese and Western; modern art

\section{INTRODUCTION}

Mr. Chu Teh-chun, born in Xiao County of Xuzhou, Jiangsu Province in 1920, studied at the Hangzhou National Art Institute in 1935, and went to France to pursue the arts road in 1955. After half a century of unremitting efforts in Paris, he became the first Asian academician in Academy of Fine Arts of the Institute of France, and was regarded as the incontrovertible drawing master in the 20th century by French critics; at the same time, he is also considered as the second generation of oil painter who revitalized Chinese art, rejuvenated Chinese painting and made outstanding contributions in promoting traditional Chinese culture in the world by the Chinese art circles.

Why can Chu Teh-chun's abstract painting be recognized by the Chinese and Western art circles at the same time? How should we evaluate his important position in the history of Chinese and Western modern art? The author makes the summary from the following three aspects.

\section{MODERNISM IN THE FUSION OF CHINESE AND WESTERN CULTURE}

The development of Chinese painting for thousands of years has formed a relatively closed system, so even the introduction of Western oil paintings in the 16th century has not have a fundamental impact on it. But after the failure of two "Opium War", the whole country was shocked. The elites realized that only learning from the West can change China, so the impact of Western culture on Chinese culture has gradually expanded. Theory of improvement in early ideological and cultural areas quickly spread to the art circle. The first person who proposed to reform the art was Kang
Youwei. After the failure of the reform movement, he quit politics, but he still has a great influence in political and cultural circles. He visited Western art in a trip to Europe, and was greatly shocked. Then he made his own judgment to Chinese painting by attributing the backwardness of Chinese art since the Ming and Qing dynasties to the little attention paid to the "shape" by freehand painting, and thought that we should learn from western sketching.

Due to the urgent needs for painting talents especially the Western painting talents of Chinese society, young overseas students returned to China to run private art schools. However, what contributes the biggest effort in promoting the development of Chinese modern art is public art school, among which the two art colleges founded by Cai Yuanpei were the most important academic center at that time. They are respectively Hangzhou National Art Institute founded in 1928 and Peking State Central University Art Department founded in 1927, which employed Lin Fengmian and Xu Beihong who returned from France to preside over the teaching in two schools respectively.

Lin Fengmian advocates "art of new era", and stands for acting according to the law of art. He uses the way of "harmonizing Chinese and Western culture" to dilute the differences between China and the West, and solve the problems of cultural differences in creative process, so that creative ideas are broaden and art language moves towards modernization. Therefore, he can both accept the Western Impressionist, Fauvism and the ancient Chinese Han and Tang art and folk art. His creation gives up the rigid law of the Western academy, but chooses the expression of modernism and integrates the ancient Chinese excellent tradition of visual experience, so as to create a new painting style. His successful artistic exploration is a very useful revelation for latter students such as Chu Teh-chun and $\mathrm{Wu}$ Guanzhong.

$\mathrm{Xu}$ Beihong teaches a set of Western classical teaching methods learned in France, which takes sketch as a basis for curriculum and promotes the realistic skill that is faithful to the object. He firmly believes that sketch is the most important as well as the basis of all the figurative art and the recipe for the treatment of Chinese painting modeling system. If Chinese art is to be revived, it must be transformed by foreign teachers. His teaching methods cultivate a large 
number of realistic artists, and also make a contribution to the modernization of Chinese art.

Although there are many differences between the "Lin school" and the "Xu School", they have made their respective contributions to the modernization of Chinese art, forming two different development tendencies of "fusion of Chinese and Western culture". However, the outbreak of the Anti-Japanese War in the late 1930s led to the important change in "fusion of Chinese and Western culture". In the urgent situation of anti-Japanese national salvation and national survival, the society has a great demand for realistic painting, so the creation of realism has risen rapidly and "realism" has become the most important value orientation in western painting. The painters turn from pursuing the form to reflecting the reality, and turn the vision to the attention paid to society and the public. Then the pluralistic value orientation of pre-war art is transformed to the situation where realism of Xu Beihong School dominates the country.

The war made Lin Fengmian school in the embarrassing position of cultural edge, so Lin Fengmian resigned from the principal's position soon and National Arts Institute also lost the status of important academic resources of modern art. Lin Fengmian and other artists becomes the undercurrent of development of Chinese modern art. There is not enough time and space for them to show their contribution and role, so they are hidden by the history because of historical reasons after the war.

From the essence of artistic creation, $\mathrm{Xu}$ Beihong transforms traditional Chinese painting with western realism. The entry point is absorbing the "scientific" method of observing and depicting the object of the Western to improve the traditional modelling of Chinese freehand painting and truly represent the artistic object to serve for the country and society by accurately shaping the image of the characters and showing the events and their meanings. However, his idea that "sketch can reflect the objective reality very realistically, and is more complete and advanced than the traditional Chinese modeling skills" is obviously restricted by the era, since the development of modern Western art has been influenced by the concept of "treasuring the meaning instead of the form" of oriental art. Too much emphasis laid on the "scientific" approach excludes the painter to explore freely in other areas, limiting the possible development of modern art language. Its strong exclusivity also make Chinese art circle with very scarce survival resources originally seriously inhibited the survival space of other different forms of art.

Lin Fengmeng lived in seclusion for many years after the resignation, focusing on exploring his modern art language. During the Cultural Revolution, he became the transformed object and even the most basic creative right was deprived. Development of modern art in China is almost in a dead state, so study in these aspects can only be continued by Chu Tehchun and others who lived abroad. In contrast, Chu Teh-chun is lucky, since he has not suspended the exploration of modern art. Since he arrived in France in 1955, he received a good development environment, with his own signing gallery. He is a professional painter with all-round guarantee, so he can focus on artistic creation completely freely. He is at the forefront of the world art trend, and beautiful traditions of France and rich culture also nurture his creation. He inherits and develops the development direction of modernism in the fusion of Chinese and Western culture of Lin Fengmian to reach a new height, which retains a rare modernist sample in the thousands of realistic faces of Chinese modern art.

Chu Teh-chun, under the influence of Lin Fengmian's esteem of modern art, begins to study the ontology language of modern painting. In the sketching, he not only learns the framing method, formal construction, and principle of light and color of impressionism, but also rethinks the problem of combination of traditional Chinese painting techniques and principle, such as the reconsideration on clouds in Eight Immortals Mountain and the ink performance of Chinese painting. In the early period of concretization in Taiwan and Paris, Chu Teh-chun adds his own subjective feelings in the paintings along the road of Cezanne and Matisse, to deal with the picture, plane or performance, and makes a lot of exploration in formal aspects.

Due to the enlightenment of "freedom" of Stael, Chu Teh-chun gives up the description of concretization. He wants to get rid of the constraint of image of the object to enter the stage of "invisible" self-expression of the abstract art. From the earliest abstract experiments, it can be seen that his deformation still need to use the city, human body and flowers to get the most basic feeling to the form and color of the picture. In order to reach a more "pure" abstraction, Chu Teh-chun turns to use the constitutive method of structuralism and enters into the stage of pure geometric abstract structure. Black lines become the main body of the picture. Although there is still a little color hinting the existence of landscape in the background, in this stage his attention has been completely concentrated in the study on the modern form language of image ontology. This period has lasted for several years since the overcautious painting status and obstruction in creative thinking can be seen from a large number of works in exploratory period. However, this stage is also the time when he received most benefit from modern Western art, such as the meaning and relationship of point, line and face in abstract structure, the expression of color, and space organization and expression and so on, which are the most basic problems of modern painting after stripping the specific image. Later, he talked about Kandinsky's influence for several times. It can be seen that he has made a great deal of hard work for formal language of modern art. Under the guidance of the goal of modern art envisaged by Lin Fengmian, Chu Teh-chun deeply absorbed the latest achievements of Western modern painting on the art itself through impressionism, fauvism and abstractionism. After the re-examination of the baptism of modernism, he no longer needs to use the body of concrete image of things, but go deep to the internal through the appearance to directly express the feelings to spirit, artistic conception, and life, thus establishing a channel for free expression among the subject and object of art.

Chu Teh-chun always uses a mix of coffee and milk to describe the deep integration of Chinese and Western cultures. He expresses the following view on the 
combination of Chinese and Western culture: "I think the painter should create on the basis of the study of Chinese and Western culture instead of knocking together rigidly. The real fusion is the fusion of Eastern and Western ideas naturally presenting in the works or it can only be called knocking together." [1]Critics Gao Tianmin thinks that Chu Teh-chun uses the Western "eyes" as the form to grasp and understand the world and enrich the world with Chinese "wisdom" as the connotation, so he can find his own unique and ingenious entry point in the tide of fusionism. His art has transcended the "fusionism" orientation in the contemporary Chinese oil painting as well as the traditional "theory of the body and function", and has become a new hope and possibility of Chinese art, providing a very important reference for the contemporary Chinese art creation. [2]

\section{The ORIENTAL IMAgE OF THE WESTERn ABSTRACT}

The origin of Western modern art comes from Cézanne's new understanding of classical realistic painting, after which his painting revolutionarily discovers a more essential pure painting element under the appearance of things, namely the self-value of formal elements. Clive Bell raises it to the aesthetic level of "meaningful form" and creates the modern formalism aesthetics, which affected the development of modern art throughout the twentieth century. Later, abstractism school completely negates the objective things, and Kandinsky thinks that art does not need to depict the visible things, but to create the invisible things. [3]Malevich said: "The things in real world have disappeared like smoke. I did not create anything, but just experienced the spirit". [4]In order to create an entirely independent and new world in the work, many abstract artists demand to cut off the connection with any objective and concrete things to achieve absolute spiritual freedom.

With the prevalence of abstract expressionism and Greenberg's admiration for minimalism, the abstract art movement also gradually declined in the 1970s. This decline is the inevitable result of historical development. At the beginning of creation, they had magnificent ideals, hoping to get out of the constraint of the objective world and enter the infinitely abundant free expression. However, things go athwart, since they found that under the so-called philosophical guidance and passionate impulses, they still can only create extremely monotonous and limited formal symbols that are even more repetitive and boring than figurative art. Because of the uncertainty and ambiguity of abstract symbols, they still need to use explanations of words and language to express clearly, which paradoxically go back to the literariness that Cezanne had strongly exclude. Historical practice proved that after leaving the objects and nature, abstract art has plunged into a mechanical and monotonous self-replication, becoming an empty shell of ideas and losing the valuable creativity of art.

Language is the tool of thinking and the languages used by Westerners since ancient times are abstract alphabetic writing, which clearly divide the relationship between speakers and things by the differences of voice, tense, gender and subject and object. This makes Westerners born with unusual abstract thinking skills, so they are particularly good at scientific exploration, invention and creation. Western culture emphasizes the role of man as the subject of cognition. From the trust in subject "I" to the trust in language, Western culture holds that "the language program is the program of truth and the clarity of language represents the clarity of the truth." [5]This kind of language worship and truth worship promote the cognitive modes of Western pursuing the essence, since "the highest level of rationality is the clear definition of a language sign". [6]Therefore, the Western abstract painting pursues the stripping of objects under the guidance of language and culture, and ultimately moves toward the pure formal structural experiments. Even the pursuit of the process of painting is a cultural internal necessity.

Chinese language is derived from hieroglyph, so the Chinese way of thinking has the characteristics of rineingism. Han nationality regards meaning as superiority to word, and always thinks the language is physical. Tao is the ultimate noumenon of the universe, which can only be understood instead of interpreted by language. To understand the object profoundly, people must surpass the "existence" (form) of the object to grasp the "invisibility" (spirit) of the object through intuition and overall impression, and thus "express the meaning without saying a word." Xu Xingyan compared the Chinese and Western languages and modes of thinking and held that features of Chinese are "holistic comprehension" and "analogy associativity", which reflect "the spirit of understanding" while Western languages are characterized by "structural analysis" and "logical deduction," reflecting the "intellectual spirit. [7] Because of the differences in cultural genes, abstract thinking is a natural endowment for the West, and for Chinese it is "acquired knowledge". If Western cultural achievements are to be developed in China, they will be filtered through the inherent rineingism and intuitive thinking mode, so Chinese art cannot be "fully Westernized."

After Chu Teh-chun went to France in 1955, he has been at the forefront of European art and knows very well about Western abstract art. The transition from concretization to abstraction is his acceptance of the art concept of "free expression" of modernism. However, he is not confined to the conceptualization of Western abstraction and separation from nature, but move towards his own unique "oriental artistic conception." He opposes the excessive conceptualization of modern art and argues that artistic practice should be given top priority and the final transition of creative ideas must rely on the works. He said: "Everything I want to express is in my paintings. The language expression is always very limited. I hope you see more works, because I am in my painting." [1]Critic Panfan believes that compared with other members of the "New Paris School," Chu Teh-chun opposes the rigid combination of the elements of East and West in formalism and thinks that the experience of life should be taken rather than the form. He deliberately keeps distance from formalism and pursues the spiritual activity to make creation freely. His works contain many Chinese ideology and Zen thought, so he find himself through practice rather than logical understanding and inference. [8] Zu Wei also thinks the 
starting points of Chu Teh-chun and Kandinsky moving toward the abstract are different. Kandinsky made various assumptions from the perspective of theoretical concept, completely deconstructing the concrete; Chu Teh-chun, influenced by the painting method of "paradox" of Stael, went from the sensibility to the abstract without any presumption of his own. He feels that abstraction allows him to vent freely and get closer to the familiar Chinese freehand painting. [9]

Chu Teh-chun also fully recognizes the importance of the object in artistic creation. He believes that the opposition between abstract and concretization should be eliminated and abstract paintings do not necessarily deny the natural image of material completely. He always insists on finding creative inspiration from nature and creates a natural and mature world of art. The viewers can not only see the abstract presentation, but also receive the art appreciation function of sightseeing and habitability of traditional Chinese landscape painting. While engaged in abstract trends, he absorbs much essence of modern art with the attitudes of research and overcome, and identifies the seductive painting schools by using his own intellect to keep away from threatening traps. Compared with the bizarre colors, distorted lines, absurd ideas and the spiritual states of turbulence, noise and riot in western abstract art, he refines the oriental imagery from the traditional Chinese philosophical thought, and transcends the anxious expression of western modern art to the "mind traveling" in the "spiritual interaction between heaven and earth alone", thus displaying the profoundness of universe in a limited space, which embodies the free-creation state of mind and body isomorphism, and creates brilliant "Chinesestyle" abstract art works.

French critic Pierre Cabana comments that Chu Teh-chun is a new link in the chain connecting the art of East and West. His creation stems from two cultures but only has one intention that constructing with touching colors to make painting speak through its whole and the free style of drawing. He transcends the boundaries and captivity of concretization and abstract, so he is an artist that cannot be categorized by words, classifications or definitions. He goes beyond any language that imprisons or confines him to a certain extent. [10]Writer Li Lincan sees the character of "going beyond the appearance and grasp the essence" that is unique to oriental in him. [11]What they describe is exactly the breakthrough of "Oriental Images" in Chu Teh-chun's works to "Western Abstraction."

\section{TRADITIONAL REVIVAL IN THE MODERN TRANSFORMATION}

The long period coexistence of Confucianism, Buddhism and Taoism in China's history is also the ideological foundation of the emergence of traditional Chinese arts. The aesthetic realm pursued by Confucianism and Taoism is the main source of the formation of the Chinese artistic spirit. And the latter Zen thoughts and its pursuit of aesthetic realm further enrich and develop the Chinese artistic spirit. The aesthetic realm of art is the Chinese ideal of life and belief, as well as the highest expression of Chinese artistic spirit. [12]
Lin Yutang said that poem enables the Chinese to penetrate deeply into society through poetry volumes, acquire the awareness of compassionate compassion and infinite affection for nature, and look on life with an artistic vision. The aesthetic realm of art is the Chinese ideal of life and belief, as well as the highest expression of Chinese artistic spirit.

Chinese traditional art has the characteristics of early maturity since the aesthetic standards of painting emerged early in Wei, Jin, Northern and Southern Dynasties. Xiehe's "Six Principles" proposed detailed requirements from all angles and endow the development of Chinese painting a correct aesthetic orientation. The strong national power in Tang Dynasty provided a solid material foundation for the prosperity of Chinese art. The emergence of landscape painting made the Chinese painting get rid of the early function of education and turn to pursue the independent aesthetic value. During Five Dynasties, there were a large number of masters who served as the link between past and future. In Song Dynasty, there was an unprecedented prosperity of Chinese painting with landscape painting and flower and bird painting reaching a level that was hard to reach by the descendants and became the later aesthetic standards. The literati painting appeared in Song Dynasty and prevailed in Yuan Dynasty. Its creative idea, ink language and style and interest were reflected in the painting practice of the later period.

However, in Ming and Qing dynasties, Chinese art lost the broad mindset of Han and Tang dynasties and the spirit of inquiry to the works of Song Dynasty. "The four painters of Wu" in Ming Dynasty advocates returning to the ancients, especially the painting idea and ink pattern of Yuan people. Dong Qichang made a summary and transformation of schema language for the experiences and achievements of literati painting, and constructed a complete genealogy of literati painting that aroused numerous controversies in later generations. His theory of "South-North schools" got both praise and blame in the history of Chinese literati painting. In Qing Dynasty, the "Four Kings" inherited Dong Qichang's theory of literati painting. While ensuring the purity of ink ancestry, they restrained their self-awareness and indulged themselves in the collocation of various "classic sachems", which deeply impacted the paintings in Qing dynasty. Their influence covered the entire Qing Dynasty to the Republic of China. The tendency of "imitating the ancient" in Ming and Qing not only lost the vivid feeling to the creation object, but also lost the initiative of the creative subject and became a modeled copy of the picture schema. Therefore, Chinese art creation lost its vitality. This decline is due to the restraint of feudal ruling class on the ideological culture. Xu Fuguan pointed out: "the method used by Chinese imperial examination system to select people transform from poetry to art and from art to eight-part essay, which devastated personality of intellectuals and occluded the hearts of intellectuals, making them insensitive mollusks ... ... they were buried in the dirty of the world. They neither had common sense of the world, nor can make for nature, so they can show off their articles for fun." [13] He found that the long-term ideological suppression of feudal autocratic makes 
the requirements and significance of freedom and liberation of spirit particularly important.

After the Opium War, China was forced to open up to the world. Then Chinese society was burdened with heavy historical burdens and pressures. On the one hand, it sought to integrate into the modern Western civilization; on the other hand, it sought to reorient and rejuvenate its own civilization. The superiority of poetic sense of China's traditional aesthetic culture showed its weakness in adapting to modern civilization facing the practical scientific and technological forces in the West. Kang Youwei and Chen Duxiu et al. completely denied the traditional Chinese culture based on the status quo of the times, which had a huge impact on Chinese society at that time. As a result, Chinese painting took the road of being improved by the West. The education after the founding of New China was also opposite to the history, and the traditional Chinese culture was criticized as the idealism thought. The "Cultural Revolution" and the attack on "Four Olds" have severely damaged the fine artistic heritage and cultural traditions. Nie Zhenbin believes that the materialism monism and the political centered thinking not only limit the development of Chinese art, but also shrink the spirit of art and cut off the long tradition of art in China. [14]

The author visited Mr. Chu Teh-chun in 2005 and talked with him about many Chinese art topics. He believed that some of China's contemporary art is outdated while others are too radical and he expressed his concern over these phenomena. In the conversation, he candidly acknowledged that what makes him benefit the most in study is the education of Chinese cultural spirit that he received from an early age and repeatedly told the author the importance of Chinese traditional culture. In his interview with Xing Xiaozhou, he said: "I always think that China is a birthplace for painter. There will also be very good painters who innovate Chinese paintings, and usher in a new era of 'Renaissance' in China. ... In current era, communication is developing and cultural exchanges are increasingly frequent, so artists can use a wide variety of present forms. However, I strongly agree with the opinion of art critic Apollinaire that works of art must have individuality, national character, and epochal character and such art is valuable." [1]

The family art education that Chu Teh-chun received in his early years was traditional copying method of Chinese paintings. When he studied in Hangzhou National Art Institute, like many early reformists, he realized that the excessive copying of ancient works kept away from the observation and feeling of nature, which lost the source of creative vitality. He lost interest in this boring method, so he turned to learn Western painting. However, after years of study in Paris and through the baptism of the Western modern abstract painting language, he had a higher viewpoint. He jumped out of the Lushan Mountain to observe its full view, and saw a clearer and overall "China." This rediscovery was the pillar and soul of his art. Through returning to Chinese ink and wash painting, calligraphy, poetry and philosophy, he gradually went deep into the inner reason of Chinese art tradition. He finally combined the modern abstract form with the traditional Chinese art spirit perfectly.

Chu Teh-chun first discovered the "beauty of rhythm" of Chinese artistic spirit in calligraphy study and obtained the rational sublimation in the perceptual activities. He used this beauty of rhythm full of "rhythms of life" to change the rigid rational structure of images influenced by Western abstraction in the early days. The picture space also excavated infinitely rich performance with the help of the "timeliness" of calligraphic art.

Through a great deal of study on ink and wash painting, he found the "life spirit" in the aesthetic forms of pictures. Chinese ink painting contains the interaction of Yin and Yang of Chinese traditional philosophy by using the simplest black and white, and the philosophy of black and white turns into "light" and "shadow" in his paintings, which becomes the entry point for the endless changes in the work space. Making images by polishing the painting with water can present infinitely rich changes in the actual and virtual situation, to help him experience the changing rhythm of the universe. Water's extension of the role of "oil" in oil paintings has changed the heavy effects in his oil painting works, making the texture of painting milder and moister and thicknesses full of rich variability, which thus creates the artistic conception of picture perfectly.

By inheriting the fine traditions of Chinese landscape painting, he absorbed the observation method of "to learn from the nature" of Chinese art and replaced the "visual" of the West by the "mental imagery" of the East, so as to transcend the appearance of nature to touch its inner soul. His works are full of profound understanding of the natural spirit and the discovery of natural beauty also lead him to go beyond realistic utility and surpass the feeling relief of pure "expressionism" in Western art.

Through the reading and comprehension of ancient Chinese poems, his rich experience in life has been sublimated. Poetry gave him an artistic outlook on life and helped him move from the real world to the spiritual free world. The transcendental perception in the poems enhances the richness and fuzziness of the "images" of the colors and shapes in his works, reaching the highest level of the "image out of images" of Chinese classical aesthetics.

In the long pursuit of art, Chu Teh-chun constantly absorbs the various nutrients of Eastern and Western cultures, $\mathrm{s}$ the vast gap between the two cultural differences, and succeeds in combining the two art traditions of Eastern and Western with the representation of abstract oil paintings, showing us the new heights that the combination of two civilizations can achieve. In particular, the Chinese composition in his paintings is richer and more profound. The influence of Chinese culture on him has not been diminished by the change of time and space, but gives even more nourishment to his painting life. As a Chinese painter, he has the responsibility of inheriting the culture and history of his own nation. He should preserve the advantages of Chinese culture and absorb the strengths of other cultures. It is precisely because of this that Chu Teh-chun is respected by art circles in various countries. 
French critic Lydia Harambourg believes that Chu Tehchun's paintings convey two cultures, and he combines the East and West cultures to create a personalized language of his own. Western artists separated the form from the meaning, while Chu Teh-chun retrieved the initial rhythm through the brush. [15]Mao Lei, former French Ambassador of China said that Chu Teh-chun's art has been inspired by the civilization with a long history and brought us into the torrent of tangible and intangible rivers of universal life for greater enjoyment. This painting is exactly from the oldest tradition in China and is carried forward in France. [16]

Pan Fan believes that Chu Teh-chun's artistic achievements represent the fruitful results of Chinese art in the process of modernization, which is a concrete result of the connection of Chinese fine arts with the world. It is the concrete achievement after more than 150 years of encounter between eastern and western art, with multiple significance. [9]Chu Ge believes that the "Chinese School" represented by Chu Teh-Chun, has bright prospects in proving that different tools and materials are not an obstacle of cultural separations. As long as we open the mind and face the call of the world all that are regarded as culture divides will be very easy to cross. From his works we can see the vision of human culture. [17]

\section{CONCLUSION}

It can be seen from the above analysis that as a member of the tide of fusion of Chinese modern art, Mr. Chu Tehchun is bold in exploration and adventure in the great changes of the times and cultures. In dealing with the relationship between traditional art and modern spirits, he made deep integration between Chinese and Western artistic spirits, and took a solid step for the development of Chinese new art. He experienced the influence of modernist art in France. When western abstraction came into a dilemma because of the separation between subject and object of creation, he confirmed the inherent law of art creation with his successful artistic practice. Through excavation of profound Chinese culture, he injected the traditional Chinese calligraphy, ink and wash spirit, traditional landscape painting and classical poetic aesthetics into the external form of modern Western abstract painting. It proves that Chinese traditional culture is extensive and profound and contains rich and valuable thinking legacy. $\mathrm{He}$ made great contribution to promoting the spread and development of Chinese traditional culture all over the world and thus was unanimously approved and respected by the East and West art circles. As a sensitive and profound artist, Chu Teh-chun pointed out the correct direction of the integration of Chinese and Western art for the development of Chinese contemporary art with the the essential reflection under the spark of art practice and thought.

\section{REFERENCES}

[1] Xing Xiaozhou. Interview with Xing Xiaozhou. //Chu Teh-chun's art exhibition. Guangzhou: Guangdong Museum of Art, 2000:26,31,30.

[2] Gao Tianmin. China's wisdom and the Western eyes. //Chu Teh-chun. Shanghai: Shanghai pictorial publishing house, 2005:27.
[3] [Russia] Kandinsky. Complete Works of Art of Kandinsky [M]. Beijing: Gold Wall Press, 2012:110.

[4] Xu Demin. Chinese Abstract Art [M]. Shanghai: Fudan University Press, 2009.261.

[5] Zhu Chaowei. Construction and reflection [M]. Shanghai: Shanghai Translation Publishing House, 2005: 256-257.

[6] Zhangfa. Chinese and Western aesthetics and cultural spirit [M]. Beijing: Peking University Press, 1997: 41

[7] Xu Xingyan. comparison between Chinese and western cultures [M]. Beijing: Peking University Press, 2004: 110

[8] Pan Fan. vigorousness, glory, Chu Teh-chun [M]. Taiwan: Publisher, 2011:130,10

[9] Zu Wei. Biography of Chu Teh-chun [M]. Shanghai: Wenhui press, 2001:147-150.

[10] [France] Pierre Cabanne. Chu Teh-chun [M]. Beijing: Sanlian Bookstore, 2000:19.

[11] [France]Pierre Cabanne. Chu Teh-chun's paintings: to express the mind and praise the nature $[\mathrm{M}] / / \mathrm{Chu}$ Teh-chun's exhibition. Guangzhou: Guangdong Museum of Art, 2000: 13.

[12] Lin Yutang. Chinese people [M]. Beijing: Xuelin press, 1994:240.

[13] Xu Fuguan. Chinese artistic spirit [M]. Liuzhou: Guangxi Normal University Press, 2007:284.

[14] Nie Zhenbin. Modern Transformation of Chinese Artistic Spirit. Beijing: Peking University Press, 2013: 410-412.

[15] Lydia Harambourg. poetry of Space//Chu Teh-chun. Shanghai: Shanghai pictorial publishing house, 2005:17.

[16] [France]Meo Lei. Introduction [M] / / Chu Teh-chun's art exhibition. Guangzhou: Guangdong Museum of Art, 2000:4.

[17] Chu Ge. On Chu Teh-chun - A Research Report on Chu Teh Chun's Painting Art. Tai Zhong: National Taiwan Museum of Fine Arts, 2004:42. 